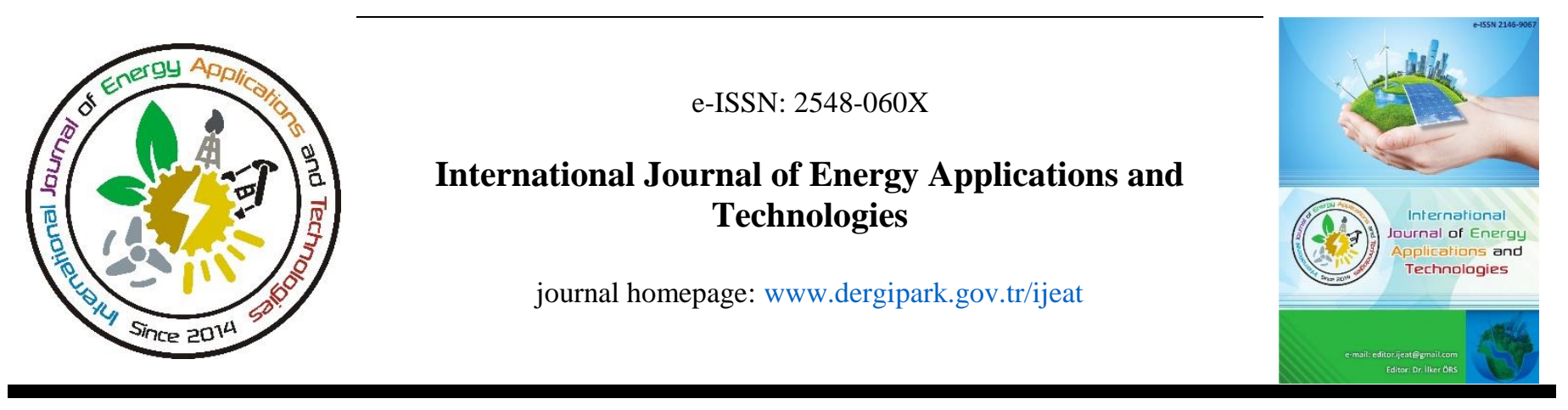

Original Research Article

\title{
Unraveling optimum culture composition for hydrogen and 5-aminolevulinic acid production by Rhodobacter sphaeroides O.U.001
}

\author{
Gökhan Kars ${ }^{1 *}$, Ümmühan Alparslan ${ }^{2}$ \\ ${ }^{I}$ Necmettin Erbakan University, Faculty of Science, Department of Molecular Biology and Genetics, 42090, Konya, Turkey \\ ${ }^{2}$ Selçuk University, Faculty of Science, Department of Biology, 42075, Konya, Turkey
}

\author{
ARTICLE INFO \\ * Corresponding author \\ gkars@erbakan.edu.tr \\ Received May 16, 2020 \\ Accepted July 8, 2020 \\ Published by Editorial Board \\ Members of IJEAT \\ (C) This article is distributed by \\ Turk Journal Park System under \\ the CC 4.0 terms and conditions. \\ doi: $10.31593 /$ ijeat. 738318
}

\begin{abstract}
The objective of this work was to reveal optimum culture composition for hydrogen and 5aminolevulinic acid productions by Rhodobacter sphaeroides O.U.001 regarding substrate concentration and supplementations of elements and vitamins. Acetate was chosen as carbon source and five distinct concentrations $(20,25,30,35$ and $40 \mathrm{mM})$ were tested in two experimental setups. While, elements $\left(\mathrm{FeSO}_{4}, 2 \mathrm{~g} \mathrm{~L}^{-1}\right.$ and $\left.\mathrm{Na}_{2} \mathrm{MoO}_{4} .2 \mathrm{H}_{2} \mathrm{O}, 0.2 \mathrm{~g} \mathrm{~L}^{-1}\right)$ and vitamins (Biotin, $0.015 \mathrm{~g} \mathrm{~L}^{-1}$, Niacin, $0.5 \mathrm{~g} \mathrm{~L}^{-1}$ and Thiamine, $0.5 \mathrm{~g} \mathrm{~L}^{-1}$ ) were added into the media in the first setup, they were omitted in the latter for comparison. As a result, the highest hydrogen production $\left(0.33 \mathrm{~L} \mathrm{H}_{2} \mathrm{~L}^{-1}\right.$ culture) was attained in the presence of supplements using $20 \mathrm{mM}$ acetate. Similarly, the maximum amount of 5-ALA generation $(16.54 \mathrm{mM})$ was achieved in $20 \mathrm{mM}$ acetate containing medium under the same conditions. On the other hand, the greatest bacterial growth $\left(\mathrm{OD}_{660}: 4.412,2.162 \mathrm{~g} \mathrm{cdw} \mathrm{L}^{-1}\right)$ was achieved in the absence of supplements using $40 \mathrm{mM}$ acetate. To conclude, while element and vitamin supplementations promoted hydrogen and 5-ALA productions, absence of these had a positive effect on cell biomass. Specifically, the medium containing $20 \mathrm{mM}$ acetate together with elements and vitamins could be suggested as the optimum growth culture for the highest hydrogen and 5-ALA productions.
\end{abstract}

Keywords: Acetate; Aminolevulinic acid; Hydrogen; Rhodobacter sphaeroides

\section{Introduction}

Rhodobacter sphaeroides is a robust microorganism which can generate several high value-added products like hydrogen [1, 2, 3], 5-aminolevulinic acid (5-ALA, 5-amino4-oxo-pentanoic acid) $[1,2]$ and poly- $\beta$-hydroxybutyric acid [4]. As being non-pathogenic and non-immunogenic [5], $R$. sphaeroides could be a safe and sustainable platform for the green generation of high value-added products. Recently, genomes of some strains have already been sequenced and molecular tools were established to be used in purple non sulfur (PNS) bacteria [6, 7]. Since the PNS bacteria have rich metabolic activities, they were employed as models for enlightening several biological events. In addition to these, their ability to generate various valuable substances made these microorganisms particularly advantageous.

Hydrogen is a chemical which can serve as both clean energy source and high value-added product. As a valuable chemical, it is used for the generation of other precious substances like ammonia in different industries. Hydrogen is not freely available in nature but it is produced through chemical and biological processes. In microorganisms, molecular hydrogen is formed by two main enzymes namely nitrogenase and hydrogenase [8]. As a matter of fact, hydrogen generation is an intrinsic feature of nitrogenase enzyme whose principle function is to convert molecular nitrogen into ammonia as shown in Equation 1. In the lack of nitrogen and under photosynthetic conditions, nitrogenase 
enzyme just acts as hydrogen evolving enzyme as depicted in Equation 2.

$\mathrm{N}_{2}+8 \mathrm{e}^{-}+8 \mathrm{H}^{+}+16 \mathrm{MgATP} \rightarrow 2 \mathrm{NH}_{3}+\mathrm{H}_{2}+16 \mathrm{MgADP}+16 \mathrm{P}_{\mathrm{i}}$

$2 \mathrm{H}^{+}+2 \mathrm{e}^{-}+4 \mathrm{ATP} \rightarrow \mathrm{H}_{2}+4 \mathrm{ADP}+4 \mathrm{P}_{\mathrm{i}}$

Recently, there is an increasing concern in the world on the use of hydrogen as a biofuel in transportation vehicles like cars. This will in turn promote the research on hydrogen production technologies. Among them, hydrogen production by microorganism has always been an attractive research topic since it is highly possible to produce hydrogen at ambient conditions in environmentally friendly processes. Additionally, capability of photosynthetic microorganisms to use sunlight energy and wide variety of carbon sources make the biological hydrogen production processes more feasible. Moreover, various high value-added products like enzymes, biopolymers and bioactive compounds could also be generated in addition to hydrogen using industrial waste streams in cost-effective bioprocesses in the context of biorefinery approach [9]. Nevertheless, biological hydrogen production conditions should be optimized in all aspects to achieve an efficient bioprocess. For instance, various effectors such as elements [10], vitamins [11], carbon [12] and nitrogen sources [13] can influence the hydrogen generation efficiency in $R$. sphaeroides. Therefore, optimum physiological conditions should be found out for each defined condition for efficient production of the hydrogen.

One of the pillars of the biological hydrogen production process is the substrate since the total reducing power of the cell is mainly determined by the type of substrate and its assimilation pathway in the cell. For instance, organic acids like lactate, malate and acetate and simple sugars like glucose and fructose could readily be used by PNS bacteria for hydrogen productions [2, 12, 14]. Among them, acetate is a two-carbon compound and its theoretical conversion into hydrogen is given in Equation 3.

$\mathrm{C}_{2} \mathrm{H}_{4} \mathrm{O}_{2}+2 \mathrm{H}_{2} \mathrm{O} \rightarrow 2 \mathrm{CO}_{2}+4 \mathrm{H}_{2}$

Acetate is the major organic acid in the dark fermentation effluents of different feedstock and it takes special attention for this reason. For example, the formation of $86 \mathrm{mM}$ acetate was reported upon dark fermentation of sugar beet molasses by Caldicellulosiruptor saccharolyticus [15]. Likewise, 76$91 \%$ of the metabolites was found to be acetate in the dark fermentation effluent of fruit and vegetable waste [16]. In sequential hydrogen production process where dark fermentation is followed by photofermantation, acetate formed during dark fermentation is further converted into hydrogen by PNS bacteria in photofermentation stage thereby increasing the efficiency of the overall process. As much as $13.7 \mathrm{~mol} \mathrm{H}_{2} \mathrm{~mol}^{-1}$ sucrose was attained in such a consecutive hydrogen generation process [15]. Therefore, as being main component of dark fermentation stream, it is essential to reveal the optimum amount of acetate required for an efficient hydrogen production in photofermentation.

The presence and amount of vitamins and elements in growth cultures are other factors which were shown to influence hydrogen production efficiency of microorganisms [10, 11]. In these reports, addition of metal ions and vitamins were proved to exhibit positive impacts on biohydrogen generation. Since each process is unique in terms of culture composition and conditions, element and vitamin supplementations should also be evaluated regarding coproduction of 5-ALA and biohydrogen.

In recent applications, exploitation of waste streams and feedstocks by multiproduct production in a single process is targeted [9]. This approach is referred as biorefinery concept. In this way, the feasibility and cost efficiency of the bioprocess is enhanced. Motivated from this approach, in the present study, the generation of 5-ALA, which is a high value-added product, was aimed in addition to hydrogen production. 5-ALA has numerous uses in health, biotechnology and agriculture [17]. For example, it is utilized as photosensitizer in photodynamic therapy to cure different types of cancer as well as biodegradable insecticide, growth factor for plants and weed killers [17]. 5-ALA can be produced and secreted into the medium by $R$. sphaeroides; therefore, it is practical and easy to harvest 5-ALA from the culture liquid after collecting hydrogen out of the bioreactor. To achieve an efficient method for co-production of hydrogen and 5-ALA, culture composition and conditions should carefully be optimized. In this context, in the present study, several experiments were designed and tested to find out the optimum culture composition for hydrogen and 5ALA productions in terms of substrate concentration (acetate) and supplementations of elements (Fe and Mo) and vitamins (Thiamine, Niacin and Biotin).

\section{Materials and Method}

\subsection{Growth media composition}

Rhodobacter sphaeroides O.U. 001 whose DSM number is 5864 was used to generate hydrogen and 5-ALA. The bacteria were routinely maintained in Biebl and Pfennig minimal medium in which malate was the carbon source [18]. However, in hydrogen and 5-ALA generation studies, the growth media were prepared using acetate instead of malate. Five distinct acetate concentrations $(20 \mathrm{mM}, 25 \mathrm{mM}, 30 \mathrm{mM}$, $35 \mathrm{mM}$ and $40 \mathrm{mM}$ ) were tested in two different experimental setups. In the first setup, element $\left(\mathrm{FeSO}_{4}, 2 \mathrm{~g} \mathrm{~L}^{-1}\right.$ and $\mathrm{Na}_{2} \mathrm{MoO}_{4} .2 \mathrm{H}_{2} \mathrm{O}, 0.2 \mathrm{~g} \mathrm{~L}^{-1}$ ) and vitamin (Biotin, $0.015 \mathrm{~g} \mathrm{~L}^{-1}$, Niacin, $0.5 \mathrm{~g} \mathrm{~L}^{-1}$ and Thiamine, $0.5 \mathrm{~g} \mathrm{~L}^{-1}$ ) solutions were included in media. In the second setup, these elements and vitamins were omitted so that effects of both acetate concentration and supplementations of elements and vitamins on hydrogen and 5-ALA productions were explored 
in this way. As a source of nitrogen, $2 \mathrm{mM}$ of glutamate was put into the media. In order to enhance 5-ALA generation by $R$. sphaeroides O.O.001, $15 \mathrm{mM}$ of levulinic acid (LA) was added into the growth media as suggested earlier [19]. LA supplementation was done toward the end of logarithmic phase of growth as recommended previously [20] so that it did not interfere with the growth and hydrogen production performance of the cells. In order to prevent drastic $\mathrm{pH}$ rises due to the use of acetate, potassium phosphate buffer $\left(\mathrm{KH}_{2} \mathrm{PO}_{4}, 0.5 \mathrm{~g} \mathrm{~L}^{-1}\right)$ which has strong buffering capacity was used in the media. Except for the modifications mentioned above, the composition of the medium was same as that of Biebl and Pfennig minimal medium.

\subsection{Culture conditions}

Hydrogen and 5-ALA hydrogen co-generation studies were accomplished in $55 \mathrm{~mL}$ glass photobioreactors under anaerobic condition which was assured by argon gas flushing through the bioreactors for about $3 \mathrm{~min}$. The cultures were incubated at $29{ }^{\circ} \mathrm{C}$ without mixing since these bacteria stay suspended in liquid media due to their flagella. The light energy ( 3 klux) for maintaining photosynthetic conditions was provided from incandescent light bulb with tungsten filament.

\subsection{Measurements and analytical techniques}

Each of growth media $(45 \mathrm{~mL})$ with defined compositions was inoculated with $5 \mathrm{~mL}$ of freshly grown cell culture. Then, the incubation of cultures was done assuring photosynthetic environs as mentioned above. Throughout the bioprocess, several measurements for turbidity, $\mathrm{pH}$ and hydrogen evolution were done. The growth of the cells was followed using a spectrophotometer (Biochrom Libra S22, UK). The turbidity measurements were done periodically at a wavelength of $660 \mathrm{~nm}$ and growth curves were drawn using these absorbance values at the end of the process. The cell dry weight $(\mathrm{cdw})$ calculations were performed knowing the fact that $1 \mathrm{OD}$ value was found to be equal to $0.49 \mathrm{~g} \mathrm{cdw} \mathrm{L}^{-1}$ culture for R. sphaeroides O.U.001 [21]. pH of the cultures was also followed during the process and the $\mathrm{pH}$ curves were sketched upon completion of the bioprocess. The collection of hydrogen gas was done until the evolution of hydrogen gas was ceased. The quantity of evolved gas was recorded periodically and then hydrogen accumulation curve for each run was plotted. The hydrogen gas was gathered in waterfilled marked glass tubes and the pureness of the gas was analyzed with a gas chromatography (Shimadzu GC-2010 Plus, Japan) having an $\mathrm{Rt}^{\mathbb{R}}$-Msieve 5A column and a thermal conductivity detector. The temperatures of detector and column were $250{ }^{\circ} \mathrm{C}$ and $50{ }^{\circ} \mathrm{C}$, respectively. Argon having a flow rate of $4 \mathrm{~mL} \mathrm{~min}^{-1}$ was utilized as an inert carrier gas. As mentioned above, 5-ALA can be generated and secreted out by $R$. sphaeroides. Therefore, the amount of 5-ALA found in the culture liquid was measured after completion of the batch processes. A technique based on color formation was applied for the calculation of 5-ALA concentration as described earlier [22]. First of all, a calibration curve was sketched using predetermined quantities of 5-ALA. Afterwards, spectrophotometric measurements of the samples were done like standard samples. Finally, unknown quantities of samples were found out from the curves through interpolation.

\subsection{Statistical analysis}

The experiments for $\mathrm{pH}$, growth and hydrogen productions were performed at least two times. The error bars representing the standard deviations from the mean values were inserted into the graphs.

\section{Results and Discussion}

\subsection{Growth and $\mathrm{pH}$ changes}

Different sorts of feedstock could be used as carbon source to sustain cell growth and high value-added product formation. In the present work, acetate was chosen as a source of carbon for the co-generation of hydrogen and 5ALA. Five different acetate concentrations (20, 25, 30, 35 and $40 \mathrm{mM}$ ) were tested. In the first setup, elements and vitamins were included in the media but they were omitted in the latter. In this experimental configuration, the effects of both the substrate concentration and supplementations of elements and vitamins on cell proliferation, hydrogen and 5ALA productions were explored.

For a substrate to be suitable for such a process, it should sufficiently sustain cell growth and should not lead to drastic $\mathrm{pH}$ changes in the growth media. For this reason, growth and $\mathrm{pH}$ changes in the media were analyzed at first. As shown in Fig 1a, elevated levels of acetate had positive impact on cell proliferation. As the concentration of acetate increased, the absorbance values (cell densities) of the cultures also increased. The rise in cell mass in response to increased acetate concentration occurred regardless of element and vitamin supplementations. Specifically, the biomass increase was more pronounced in the absence of supplements such that the maximum absorbance value $\left(\mathrm{OD}_{660}: 4.412,2.162 \mathrm{~g}\right.$ cdw $\mathrm{L}^{-1}$ ) was observed in medium with $40 \mathrm{mM}$ acetate. On the other hand, the highest optical density recorded at $660 \mathrm{~nm}$ was $3.552\left(1.740 \mathrm{~g} \mathrm{cdw} \mathrm{L}^{-1}\right)$ in the case of supplementing elements and vitamins into $40 \mathrm{mM}$ acetate containing medium. The lack of elements and vitamins probably hampered the synthesis of functional enzymes enrolled in hydrogen production process so that a great proportion of cellular materials were used for cell growth. In previous findings and this work, it was found out that the use of acetate as carbon source resulted in higher cell masses compared to the cases where malate [14] and waste barley [2] were utilized as carbon sources. Similarly, it was claimed in a 
previous study that elevated levels of acetate enhanced the proliferation of Rhodobacter capsulatus, which is a PNS bacterium, as well [23]. Specifically, $0.86 \mathrm{~g} \mathrm{cdw} \mathrm{L}^{-1}$ was achieved utilizing $65 \mathrm{mM}$ of acetate in that study. These findings support the aforementioned argument. Additionally, it could be derived from these results that acetate, even at lower concentrations, sustains the proliferation of $R$. sphaeroides significantly. Lastly, it can be deduced from the results of this study and previous findings, $R$. sphaeroides reached higher cell masses than $R$. capsulatus in the case of using acetate as carbon source. Based on these results, acetate can definitely be proposed as an effective carbon source in order to achieve high cell proliferation and cell masses.

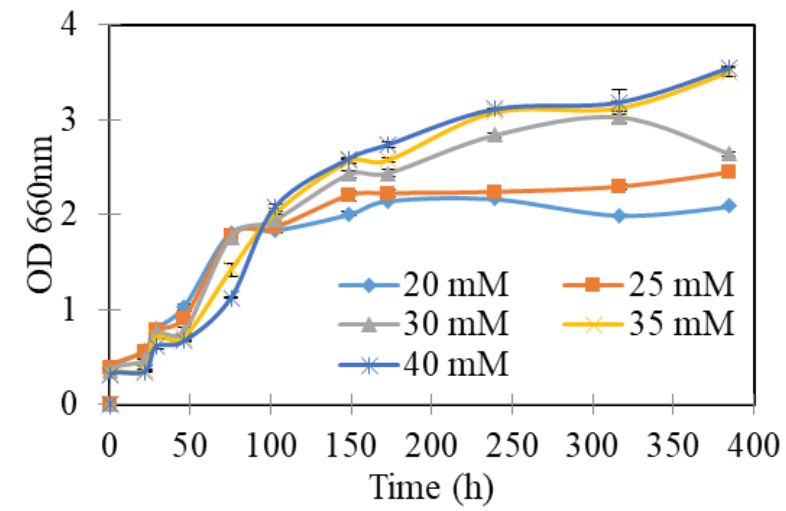

(a)

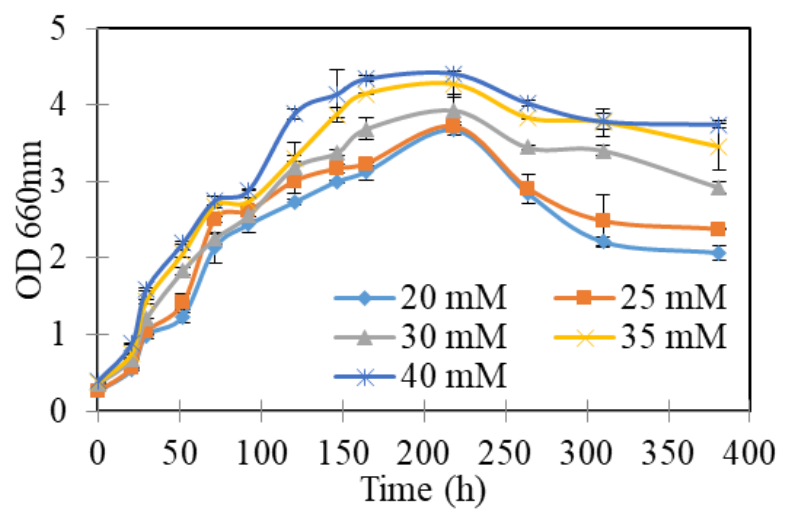

(b)

Fig. 1. Growth on acetate in the presence (a) and in the absence (b) of elements and vitamins

The change in $\mathrm{pH}$ was followed during the process because $\mathrm{pH}$ was stated to have an influence on photoproduction of hydrogen [24]. Moreover, it was realized that $\mathrm{pH}$ of the culture was considerably affected by the type of substrate [1, 25]. It can be inferred from these results that substrate not only supports the metabolisms of the cells but also it has a determinative role in $\mathrm{pH}$ of the culture. In the study, although the $\mathrm{pH}$ of the growth media was initially fixed to 7 using potassium phosphate buffer, variations from this value still occurred as shown in Fig. 2. Indeed, severe $\mathrm{pH}$ rises were prevented due to strong buffering capacity of potassium phosphate buffer. Furthermore, element and vitamin additions did not give rise to significant differences in $\mathrm{pH}$ values as seen in Fig 2. In Fig $2 \mathrm{a}$ and Fig $2 \mathrm{~b}$, the $\mathrm{pH}$ first rose up to 8 at around $100^{\text {th }} \mathrm{h}$. and then continued at this point with tiny deviations until the completion of bioprocess. This result imply that cultures were successfully buffered so that drastic deviations in $\mathrm{pH}$ did not occur and existing variations did not interfere with the cell growth and generations of hydrogen and 5-ALA.

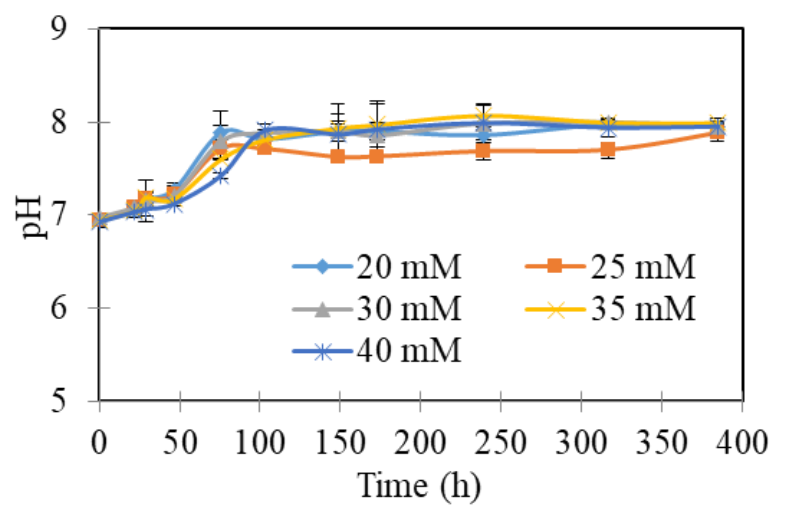

(a)

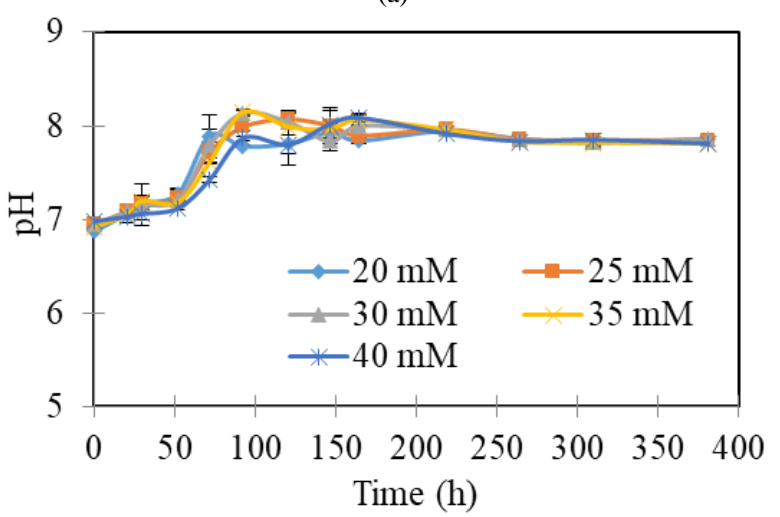

(b)

Fig. 2. pH changes in media prepared in the presence (a) and in the absence (b) of elements and vitamins

\subsection{Hydrogen accumulations}

In this part of the study, the influences of varying acetate concentrations and supplementations of elements and vitamins on hydrogen productions were investigated by testing five different acetate concentrations (20, 25, 30, 35 and $40 \mathrm{mM}$ ). Firstly, time dependent hydrogen gas accumulation in the cultures was recorded and then hydrogen production curves were constructed for each run (Fig. 3). As seen from the figure, the elevated levels of acetate had an adverse impact on hydrogen formation capability of the cells in the presence and absence of supplementations. There could be several reasons for this negative effect. First, increased acetate amounts may have promoted the generation of other metabolites or storage materials exhausting the available reducing equivalents in the cells. Second, high acetate concentrations may have resulted in osmotic stress which may then have had negative effects on nitrogenase enzyme that has the responsibility for the formation of 
hydrogen in $R$. sphaeroides. If Fig 1 and Fig. 3 were compared, it could be noticed that high acetate concentrations enhanced growth but lowered hydrogen generations. Therefore, it is more likely that high acetate concentration specifically interfered with either one of the substrates for hydrogen production like reducing equivalents and ATP or any of the responsible proteins and enzymes in the pathway. A very similar result was reported by Özgür et al. [26] in their study where R. capsulatus was cultured at various acetate concentrations for hydrogen production. They found out that increasing acetate concentration above $30 \mathrm{mM}$ led to a decrease in all hydrogen related parameters like hydrogen production yield and productivity but the biomass still continued to increase. It can be inferred from these results that above a threshold concentration acetate starts to poison hydrogen generation though bacterial growth stays unaffected.

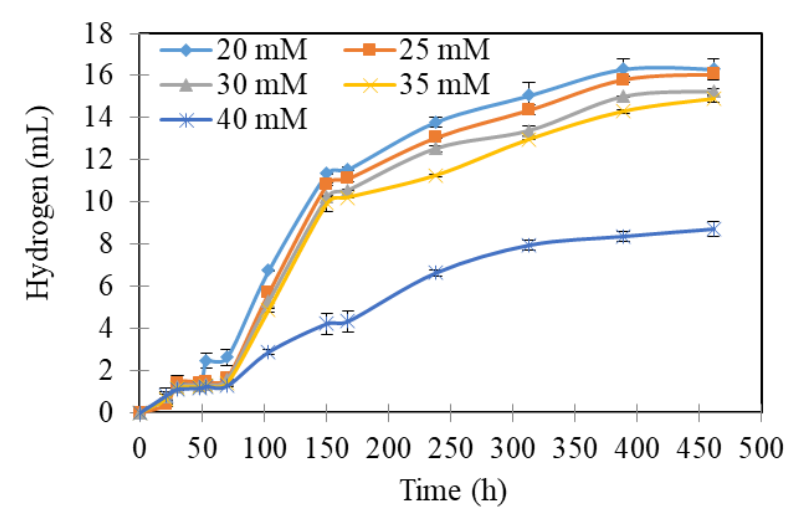

(a)

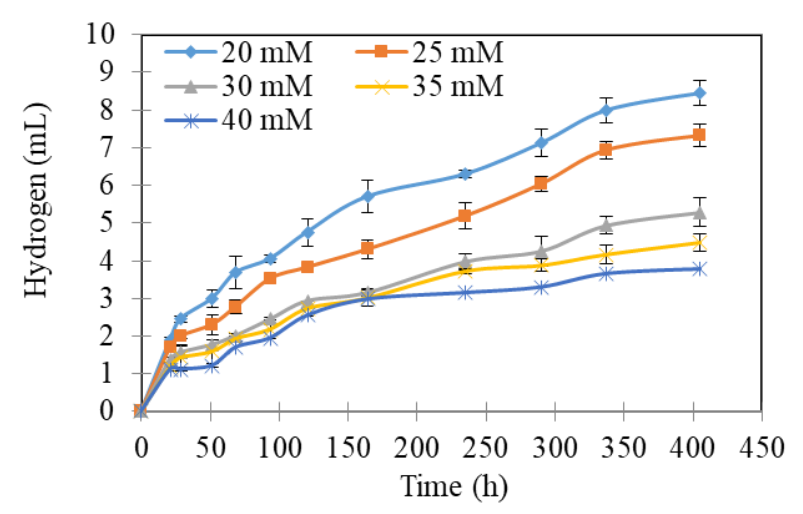

(b)

Fig. 3. Total hydrogen accumulations in media prepared in the presence (a) and in the absence (b) of elements and vitamins

In the case when elements and vitamins were added into the growth media, a slight decline in hydrogen accumulation was experienced as the concentration of acetate increased. 16.32 $\mathrm{mL}, 16.06 \mathrm{~mL}, 15.24 \mathrm{~mL}$ and $14.89 \mathrm{~mL}$ of hydrogen was collected in $20 \mathrm{mM}, 25 \mathrm{mM}, 30 \mathrm{mM}$ and $35 \mathrm{mM}$ acetatecontaining cultures. However, this decrease was more evident in $40 \mathrm{mM}$ acetate containing medium where only $8.72 \mathrm{~mL}$ of hydrogen was obtained. The highest hydrogen accumulation was recorded in $20 \mathrm{mM}$ acetate medium as being $0.33 \mathrm{~L} \mathrm{H}_{2} \mathrm{~L}^{-1}$ culture. In the case when element and vitamin supplementations were omitted, at maximum, $0.17 \mathrm{~L}$ $\mathrm{H}_{2} \mathrm{~L}^{-1}$ culture was achieved using $20 \mathrm{mM}$ acetate. As seen from the curves in Fig. 3, excluding the elements and vitamins from the growth media caused a drastic decrease in hydrogen generation. These results demonstrated that elements $\left(\mathrm{FeSO}_{4}, 2 \mathrm{~g} \mathrm{~L}^{-1}\right.$ and $\left.\mathrm{Na}_{2} \mathrm{MoO}_{4} .2 \mathrm{H}_{2} \mathrm{O}, 0.2 \mathrm{~g} \mathrm{~L}^{-1}\right)$ and vitamins (Biotin, $0.015 \mathrm{~g} \mathrm{~L}^{-1}$, Niacin, $0.5 \mathrm{~g} \mathrm{~L}^{-1}$ and Thiamine, $\left.0.5 \mathrm{~g} \mathrm{~L}^{-1}\right)$ were crucial for efficient hydrogen production by $R$. sphaeroides. In a previous study, $0.21 \mathrm{~L} \mathrm{H}_{2} \mathrm{~L}^{-1}$ culture was reported to be produced using $30 \mathrm{mM}$ acetate [25], but in the present culture composition and conditions, $0.31 \mathrm{~L} \mathrm{H}_{2} \mathrm{~L}^{-1}$ culture was achieved using the same acetate concentration. Even, the highest amount was obtained by lowering the acetate amount to $20 \mathrm{mM}\left(0.33 \mathrm{~L} \mathrm{H}_{2} \mathrm{~L}^{-1}\right.$ culture $)$. As a result of this study, it was proved that amount of hydrogen could be enhanced just by optimizing culture composition and condition. And, $20 \mathrm{mM}$ acetate with elements and vitamins could be recommended as optimum since the highest hydrogen amount $\left(0.33 \mathrm{~L} \mathrm{H}_{2} \mathrm{~L}^{-1}\right.$ culture, ) and hydrogen production yield $\left(0.025 \mathrm{~g} \mathrm{H}_{2} / \mathrm{g}_{\text {substrate }}\right)$ were obtained. Özgür et al. [26] reported various hydrogen production yields $(0.018$ - $0.088 \mathrm{~g} \mathrm{H}_{2} \mathrm{~g}^{-1}$ substrate) using acetate by $R$. capsulatus and the maximum hydrogen production yield $\left(0.025 \mathrm{~g} \mathrm{H}_{2} / \mathrm{g}_{\text {substrate }}\right)$ obtained in this study is concordant with these results. The amount of hydrogen achieved in the present study is also comparable with the amount $\left(0.4 \mathrm{~L} \mathrm{H}_{2} \mathrm{~L}^{-1}\right.$ culture $)$ obtained utilizing barley extract as feedstock where the quantity of simple sugar was $11 \mathrm{~g} \mathrm{~L}^{-1}$ [2]. On the other hand, relatively higher quantities of hydrogen were reported in case of using malate (2.85 $\mathrm{L} \mathrm{H}_{2} \mathrm{~L}^{-1}$ culture) [14] and sugar beet molasses (1.01 L H $\mathrm{L}^{-1}$ culture) [1].

\subsection{5-Aminolevulinic acid productions}

After completion of the bioprocesses, the insoluble materials like cells and cell debris were removed from the culture media. Then, the extracellular amount of 5-ALA was measured in each purified culture liquid. Similar to the results obtained in hydrogen production studies, high initial acetate concentrations plagued 5-ALA generation in the cell so that less amount of 5-ALA was accumulated in response increase in acetate concentration. On the other hand, additions of elements and vitamins improved 5-ALA generation so that considerably higher quantities of 5-ALA were attained in the presence of supplements. Specifically, $16.54 \mathrm{mM}, 15.26$ $\mathrm{mM}, 13.54 \mathrm{mM}, 3.32 \mathrm{mM}$ and $2.42 \mathrm{mM}$ of 5-ALA were generated in $20 \mathrm{mM}, 25 \mathrm{mM}, 30 \mathrm{mM}, 35 \mathrm{mM}$ and $40 \mathrm{mM}$ acetate containing-media, respectively. On the contrary, exclusion of elements and vitamins caused less 5-ALA accumulation such that only $7.33 \mathrm{mM}, 1.43 \mathrm{mM}, 0.69 \mathrm{mM}$ and $0.38 \mathrm{mM}$ of 5-ALA were generated in $20 \mathrm{mM}, 25 \mathrm{mM}$, $30 \mathrm{mM}$ and $35 \mathrm{mM}$ acetate-containing cultures, respectively. Moreover, no 5-ALA formation was observed at all in $40 \mathrm{mM}$ 
acetate-containing medium. This result could be interpreted in a way that omitting vitamin and element additions might create a stress condition for the cells so that they directed much of their energy and reducing equivalents for the production storage materials or cell biomass rather than producing metabolites like hydrogen and 5-ALA. In Table 1, various quantities of 5-ALA which were produced by different strains of $R$. sphaeroides were given for comparison. Among them, R. sphaeroides O.U.001 comes out as a potential 5-ALA producer since it can generate substantial amount of 5-ALA by assimilating various carbon sources. Particularly, higher amount of 5-ALA (16.54 mM) was achieved using acetate when compared to other carbon sources like waste barley, glucose and glycine. These results imply that acetate could sufficiently sustain the production of 5-ALA especially in case of supplementing the media with aforementioned elements and vitamins. Considering LA supplementation, there is compelling evidence that LA addition alone is not sufficient to drive the formation of 5ALA since there was no 5-ALA generation in $40 \mathrm{mM}$ acetate containing medium in case elements and vitamins were not added. Most probably, LA showed its promoting effect upon provision of all limiting factors like elements and vitamins in the cultures.

Table 1. The amounts of 5-aminolevulinic acid produced by different strains of $R$. sphaeroides

\begin{tabular}{cccc}
\hline Strain & 5-ALA $(\mathbf{m M})$ & Substrate & Reference \\
\hline O.U.001 & $16.54^{*}$ & Acetate & This work \\
O.U.001 & 23.34 & Molasses & {$[1]$} \\
O.U.001 & 0.067 & Waste barley & {$[2]$} \\
CR-606 & 11.20 & Glucose and glycine & {$[27]$} \\
CR-720 & 27.50 & Glucose and glycine & {$[28]$} \\
\hline * The amount of 5-ALA obtained in 20 mM acetate containing \\
medium supplemented with elements and vitamins.
\end{tabular}

\section{Conclusions}

Hydrogen and 5-ALA are the two valuable metabolites which are generated through the action of several enzymes in photosynthetic microorganisms such as $R$. sphaeroides O.U.001. And, several intrinsic and environmental factors have determinative roles in the overall efficiency of the production process. In this context, various acetate concentrations and supplementations of elements ( $\mathrm{Fe}$ and Mo) and vitamins (Thiamine, Niacin and Biotin) were evaluated to find out the optimum experimental configuration for the best hydrogen and 5-ALA productions by $R$. sphaeroides O.U.001. As a conclusion, $20 \mathrm{mM}$ of acetate was found to be the optimum amount for both hydrogen and 5-ALA generations while higher initial acetate concentrations seemed to plague their productions. Moreover, supplementation of elements and vitamins resulted in enhanced generation of hydrogen $\left(0.33 \mathrm{~L} \mathrm{H}_{2} \mathrm{~L}^{-1}\right.$ culture) and 5-ALA (16.54 mM). Conversely, significant amount of bacterial biomass $\left(2.162 \mathrm{~g} \mathrm{cdw} \mathrm{L}^{-1}\right)$ was attained utilizing elevated quantities of acetate $(40 \mathrm{mM})$ in the absence of elements and vitamins. In addition to these, LA supplementation alone seemed insufficient for triggering 5ALA biosynthesis. However, it is more likely that its addition into the cultures towards the end of the logarithmic phase of growth had a positive impact on the production of 5-ALA. Based on these results, the medium containing $20 \mathrm{mM}$ acetate together with elements, vitamins and LA could be suggested as optimum for co-production of hydrogen and 5-ALA. Furthermore, the idea of producing more than one valuable product was implemented by producing hydrogen and 5ALA simultaneously thereby increasing the overall cost efficiency of the bioprocess.

Acknowledgement

This study was supported by Selçuk University with the project number BAP-11401112.

\section{ORCID}

Gökhan Kars

0000-0002-2507-2305

Ümmühan Alparslan 0000-0002-4107-3420

\section{References}

[1] Kars, G. and Alparslan, Ü. 2013. Valorization of sugar beet molasses for the production of biohydrogen and 5aminolevulinic acid by Rhodobacter sphaeroides O.U.001 in a biorefinery concept. International Journal of Hydrogen Energy, 38, 14488-14494.

[2] Kars, G. and Ceylan, A. 2013. Biohydrogen and 5aminolevulinic acid production from waste barley by Rhodobacter sphaeroides O.U.001 in a biorefinery concept. International Journal of Hydrogen Energy, 38, 5573-5579.

[3] Al-Mohammedawi, H.H., Znad, H. and Eroğlu, E. 2019. Improvement of photofermentative biohydrogen production using pre-treated brewery wastewater with banana peels waste. International Journal of Hydrogen Energy, 44(5), 2560-2568.

[4] Ghimire, A., Valentino, S., Frunzo, L., Pirozzi, F., Lens, P.N.L. and Esposito, G. 2016. Concomitant biohydrogen and poly- $\beta$-hydroxybutyrate production from dark fermentation effluents by adapted Rhodobacter sphaeroides and mixed photofermentative cultures. Bioresource Technology, 217, 157-164.

[5] Kwon, S.Y., Jiang, S.N., Zheng, J.H., Choy, H.E. and Min, J.J. 2014. Rhodobacter sphaeroides, A novel tumor-targeting bacteria that emits natural near-infrared fluorescence. Microbiology and Immunology, 58, 172179.

[6] Choudhary, M., Zanhua, X., Fu, Y.X. and Kaplan, S. 2007. Genome analyses of three strains of Rhodobacter 
sphaeroides: evidence of rapid evolution of chromosome II. Journal of Bacteriology, 189(5), 19141921.

[7] Jaschke, P.R., Saer, R.G., Noll, S. and Beatty, J.T. 2011. Modification of the genome of Rhodobacter sphaeroides and construction of synthetic operons. Methods in Enzymology, 497, 519-538.

[8] Liang, J. and Burris, H.R. 1988. Hydrogen burst associated with nitrogenase-catalyzed reactions. Proceedings of the National Academy of Sciences, 85, 9446-9450.

[9] Ahmed, P.M., Fernández, P.M., de Figueroa, L.I.C. and Pajot, H.F. 2019. Exploitation alternatives of olive mill wastewater: production of value-added compounds useful for industry and agriculture. Biofuel Research Journal, 22, 980-994.

[10] Gabrielyan, L., Hakobyan, L. and Trchounian, A. 2016. Comparative effects of $\mathrm{Ni}(\mathrm{II})$ and $\mathrm{Cu}(\mathrm{II})$ ions and their combinations on redox potential and hydrogen photoproduction by Rhodobacter sphaeroides. Journal of Photochemistry \& Photobiology, B: Biology, 164, 271-275.

[11] Li, X., Shi, H., Wang, Y., Zhang, S., Chu, J., Zhang, M., Huang, M. and Zhuang, Y. 2011. Effects of vitamins (nicotinic acid, vitamin B1 and biotin) on phototrophic hydrogen production by Rhodobacter sphaeroides ZX5. International Journal of Hydrogen Energy, 36, 96209625.

[12] Hakobyan, L., Gabrielyan, L. and Trchounian, A. 2019. Biohydrogen by Rhodobacter sphaeroides during photo-fermentation: Mixed vs. sole carbon sources enhance bacterial growth and $\mathrm{H}_{2}$ production. International Journal of Hydrogen Energy, 44, 674679.

[13] Kim, M.S., Kim, D.H., Cha, J. and Lee, J.K. 2012. Effect of carbon and nitrogen sources on photofermentative $\mathrm{H}_{2}$ production associated with nitrogenase, uptake hydrogenase activity, and PHB accumulation in Rhodobacter sphaeroides KD131. Bioresource Technology, 116, 179-183.

[14] Kars, G., Gündüz, U., Rakhely, G., Yücel, M., Eroğlu, İ. and Kovacs, L.K. 2008. Improved hydrogen production by uptake hydrogenase deficient mutant strain of Rhodobacter sphaeroides O.U.001. International Journal of Hydrogen Energy, 33(12), 3056-3060.

[15] Özgür, E., Mars, A.E., Peksel, B., Louwerse, A., Yücel, M., Gündüz, U., Claassen, M.A.P. and Eroğlu, İ., 2010. Biohydrogen production from beet molasses by sequential dark and photofermentation. International Journal of Hydrogen Energy, 35, 511-517.

[16] Pascualone, M.J., Costa, M.B.G. and Dalmasso, P.R. 2019. Fermentative biohydrogen production from a novel combination of vermicompost as inoculum and mild heat-pretreated fruit and vegetable waste. Biofuel Research Journal, 23, 1046-1053.

[17] Sasaki, K., Watanabe, M., Tanaka, T. and Tanaka, T. 2002. Biosynthesis, biotechnological production and applications of 5-aminolevulinic acid. Applied Microbiology and Biotechnology, 58, 23-29.

[18] Biebl, H. and Pfennig, N. Isolation of member of the family Rhodosprillaceae, in: Starr, M.P., Stolp, H., Trüper, H.G., Balows, A. and Schlegel, H.G., The prokaryotes, Springer, New York, 1981, 267-273.

[19] Sasaki, K., Tanaka, T., Nishizawa, Y. and Hayashi, M. 1990. Production of a herbicide, 5-aminolevulinic acid, by Rhodobacter sphaeroides using the effluent waste from an anaerobic digestor. Applied Microbiology and Biotechnology, 32, 727-731.

[20] Choi, C., Hong, B.S., Sung, H.C., Lee, H.S. and Kim, J.H. 1999. Optimization of extracellular 5aminolevulinic acid production from Escherichia coli transformed with ALA synthase gene of Bradyrhizobium japonicum. Biotechnology Letters, 21, 551-554.

[21] Waligorska, M., Seifert, K., Szymanska, K. and Laniecki, M., 2006. Optimization of activation conditions of Rhodobacter sphaeroides in hydrogen generation process. Journal of Applied Microbiology, $101,775-784$

[22] Mauzerall, D. and Granick, S. 1956. The occurrence and determination of $\delta$-aminolevulinic acid and porphobilinogen in urine. Journal of Biological Chemistry, 219, 435-446.

[23] Demiriz, B.O., Kars, G., Yücel, M., Eroğlu, İ. and Gündüz, U. 2019. Hydrogen and poly- $\beta$ hydroxybutyric acid production at various acetate concentrations using Rhodobacter capsulatus DSM 1710. International Journal of Hydrogen Energy, 44(32), 17269-17277.

[24] Laurinavichene, T. and Tsygankov, A. 2018. Inoculum density and buffer capacity are crucial for $\mathrm{H}_{2}$ photoproduction from acetate by purple bacteria. International Journal of Hydrogen Energy, 43(41), 18873-18882.

[25] Kars, G., Gündüz, U., Yücel, M., Rakhely, G., Kovacs, L.K. and Eroğlu, İ. 2009. Evaluation of hydrogen production by Rhodobacter sphaeroides O.U.001 and its hupSL deficient mutant using acetate and malate as carbon sources. International Journal of Hydrogen Energy, 34, 2184-2190.

[26] Özgür, E., Uyar, B, Öztürk, Y., Yücel, M., Gündüz, U. and Eroğlu, İ. 2010. Biohydrogen production by Rhodobacter capsulatus on acetate at fluctuating temperatures. Resources, Conservation and Recycling, 54(5), 310-314. 
[27] Nishikawa, S., Watanabe, K., Tanaka, T., Miyachi, N., Hotta, Y. and Murooka, Y. 1999. Rhodobacter sphaeroides mutants which accumulate 5aminolevulinic acid under aerobic and dark conditions. Journal of Bioscience and Bioengineering, 87(6), 798804.

[28] Kamiyama, H., Hotta, Y., Tanaka, T., Nishikawa, S. and Sasaki, K. 2000. Production of 5-aminolevulinic acid by a mutant strain of a photosynthetic bacterium. Seibutsu Kogaku Kaishi, 78, 48-55. 